\title{
RESOURCES FOR PARENTS RAISING A DISABLED CHILD IN THE UK
}

Christopher Morris

Sharon Blake

Anna Stimson

Aleksandra Borek

Kath Maguire

All authors from Peninsula Cerebra Research Unit (PenCRU), University of Exeter Medical School, except Kath Maguire, Public Involvement Team, PenCLAHRC, University of Exeter Medical School.

Published in Paediatrics and Child Health doi:10.1016/i.paed.2016.04.019

Available online 19 May 2016

Max word count -1500

\section{Address for correspondence}

Christopher Morris

PenCRU, Child Health Group

University of Exeter Medical School

Veysey Building

Salmon Pool Lane

EX2 4SG

UK

christopher.morris@exeter.ac.uk 
Childhood disability is relatively common, estimated to affect around 7\% of children in the UK.[1] Nevertheless, caring for a child with medical, social and/or educational needs is not something parents expect or plan for. Parent carers often describe this unanticipated role as 'an ongoing battle' to access information and services. The aim of this article is to raise awareness of resources that can support parent carers and their families.

From the beginning parent carers need accurate information about their child's health and medical condition - what it is and what it means - and ongoing support in developing their understanding, so they can make informed decisions about treatments and therapies. Given that children have widely varying health conditions, and that parent carers and their families will also have a range of different needs and abilities, it is not possible to provide a comprehensive practical guide for professionals that will be relevant to, and meet the needs of, all the families they will encounter. Nevertheless we seek to offer clinicians some useful reflections on how they can support parent carers.

Knowledgeable, understanding and experienced professionals can be a key source of support for disabled children and parent carers. The way in which clinicians communicate with parents of children with medical conditions is crucial. Whether a family identifies that their child may have a health condition, or they are referred by another professional, it is vital that they are trusted and treated with respect and empathy. Thoughtful counselling has an important lasting impact on parents, whether during diagnostic investigations, or at the time of disclosure of diagnosis, or even when a specific diagnosis cannot be found.[2]

As well as delivering 'medical facts', it is possible to promote a child's capabilities and strengths rather than focusing on impairments and deficits.[3] Early intervention professionals, like Portage workers, provide practical tips and help to empower parents in the day-to-day management of their child at home during the initial stages of adapting to parenting a child with additional needs. These are often valued immensely by parent carers.

All Local Authorities offer a Family Information Service to provide information about local services for all families with disabled children up to the age of 25 years,[4] and an Information, Advice and Support Service relating particularly to school issues.[5] Effective multi-agency working is central to implementing the new Education, Health and Social Care Plans, and of vital importance when children transition between schools and into adult services. 
Accessing support from multiple professionals and service providers can be challenging to navigate and parents can feel overwhelmed. Expert clinicians acquire knowledge of the wider professional network supporting disabled children in their area so they can inform and signpost families as and when needs and circumstances arise, while being mindful of how many different professionals are involved in a child's care. Key workers can improve and optimise efficiency of how professional resources are utilised, and improve communication, with benefits to families and services. $[6,7]$ Parent carers can also be signposted to the Council for Disabled Children's Expert Parent Training to develop their knowledge and confidence when dealing with the health system and professionals.

The UK is a signatory to the United Nations Conventions on both the Rights of the Child, and the Rights of Persons with Disabilities. These impose statutory legal duties on the state and public bodies. Many people are unaware of their rights, they may be disempowered from attaining their rights, or stigma may prevent them from seeking their rights. Organisations that advocate, lobby and campaign on behalf of disabled people and help them to claim their rights are a vital resource.[8] For example, families in the UK may be entitled to financial assistance. However, completing the required forms to apply for financial support requires parents to catalogue their child's difficulties; hence it can be a disheartening experience. Guides, such as that provided by the charity Cerebra, explain how the form needs to be completed to obtain appropriate entitlements.[9]

A key challenge for many parent carers is to find appropriate and affordable childcare, especially after school and during school holidays.[10] Childcare offers children an opportunity to learn and experience life outside their families; it also enables parents to have time to work, or simply take a break, and develop their personal identity additional to their role as a carer.

Assistive technologies include augmentative and alternative communication aids, wheelchairs and other mobility aids, and orthoses. It is not enough that these technical resources are available; services providing equipment need to be accessible and affordable, and responsive to changing circumstances, especially when there are faults or need for repairs. Families with disabled children need their environments to be accessible so they can lead ordinary lives. Whilst much has been done to improve the accessibility of communities, basic necessities are still lacking; for instance fully accessible toilets are not adequate for many families' needs.[11] 
People that families with disabled children encounter in their everyday life can be supportive; sadly, they can also be unaccommodating or, at worst, offensive. A survey of families of disabled children in the UK reported that the negative attitudes they encountered in the community were felt to be more disabling than their child's impairments.[12] Greater effort is required to promote positive public attitudes towards disability, and to challenge misconceptions about capability for inclusion. Clinicians can play a key role in supporting charities and other initiatives advocating for societal changes in attitudes and behaviour by improving the public understanding disability. Obviously this requires a modern comprehension of disability (for information see www.disabilitymatters.org.uk).

When seeking information the first port of call is now the Internet. Information is frequently shared between families, and increasingly this is facilitated by online forums/blogs. While it is sensible to advise some caution about the generalisability of experiences between families in different situations, this can be a powerful, accessible and trusted source of practical advice about problemsolving provided by those who have overcome specific challenges and difficulties. Parent carers can find it particularly useful to make contact with other families with the same diagnosis, developmental or management challenge, especially if they have a rare condition and are unlikely to encounter anyone with the same condition locally.

There is a plethora of websites providing information of varying quality about conditions, treatments and therapies. It is important to support effective information-seeking by providing guidance on how to find reliable sources and interpret the material analytically. Signposting accurate and reliable information can help inform meaningful joint decision-making by families and professionals. So it is essential that professionals make themselves aware of relevant websites and sources of plainlanguage evidence summaries about the effectiveness of interventions.

Emotional support from other parent carers who have similar experiences can be accessed through peer support groups or one-to-one befriending services. There are many benefits of peer support, including learning from each other by sharing experiences and practical advice, and being inspired by others.[8] Peer support offers parent carers a chance to find a shared social identity, which can have positive and protective health effects; [13] the perception that there are others who are in the same boat' helps validating parent carers' experiences. Moreover, peer support can facilitate a process of personal growth, and eventually, help develop the ability to support others [14], which also benefits a person offering support (known as the 'helper-therapy principle').[15, 16] Charities too can reduce the isolation and helplessness that some families experience by supporting families, and often 
complementing formal health and social care services. Clinicians should be familiar with both national and local peer support services so that they can signpost to them.

Parent carers are a vital resource for themselves and their family, and their health and wellbeing merits greater attention. The health status of parents of disabled children in the UK is difficult to ascertain as parent carers are not readily identifiable in census or primary care datasets. Data from Canada suggest primary carers of children with complex health needs have an increased risk of physical and psychological health problems,[17] which are pervasive and may worsen over time.[18] Some parent carers may be reluctant to seek help for fear that their parenting capability might be judged. Symptoms or signs of concern may first become apparent to clinicians working with the child and family - and it is imperative that clinicians respond actively and appropriately when concerns arise, for instance by showing compassion, emphasising the need for parents to prioritise their own health and wellbeing, and by signposting medical or other help as appropriate. Think of this as 'giving parents permission' to care for themselves in the service of their child and family. Parent carers are also eligible for 'carer's assessments' to obtain personalised advice and support.[19]

\section{Conclusion}

In a short article we can describe only a fraction of the resources that parent carers of disabled children require to live ordinary lives; inevitably it has a UK focus. Nevertheless we hope the article provides a resource for clinicians and others, and helps them to reflect on the support needed by families. We have provided links which may be helpful in Box 1.

Lastly, many parent carers become experts in disability and their personal circumstances; as such they are themselves an incredibly rich resource from whom professionals and researchers can learn by listening to them, consulting them about services, and collaborating with them in research.[20]

\section{Acknowledgements}

Some of the content of this article evolved from a chapter 'Resources for people with cerebral palsy and their families' in the book Cerebral Palsy: Science and Clinical Practice published by Mac Keith Press. The authors are grateful to Peter Rosenbaum for his contributions and inspiration. We are also grateful to members of the PenCRU Family Faculty for their advice on resources to include. 


\section{References}

1. Blackburn CM, Spencer NJ, Read JM: Prevalence of childhood disability and the characteristics and circumstances of disabled children in the UK: secondary analysis of the Family Resources Survey. BMC Pediatr 2010, 10:21.

2. Baird G, McConachie H, Scrutton D: Parents' perceptions of disclosure of the diagnosis of cerebral palsy. Archives of Disease in Childhood 2000, 83:475-480.

3. Rosenbaum P, Gorter JW: The 'F-words' in childhood disability: I swear this is how we should think! Child: Care, Health and Development 2012, 38:457-463.

4. Kids O, nafis, Family and Childcare Trust, in Control.: The Family Information Service SEND Framework.

http://www.councilfordisabledchildren.org.uk/media/744916/mip2 family information ser vice send framework.pdf; 2014.

5. Information, Advice and Support Services Network (IASS Network) [http://www.iassnetwork.org.uk/]

6. Liabo K, Newman T, Stephens J, Lowe K: A Review of Key Worker Systems for Disabled Children and the Development of Information Guides for Parents, Children and Professionals. . Cardiff: Wales Office for Research and Development.; 2001.

7. Mengoni S, Bardsley J, Oates J: An evaluation of key working for families of children and young people with special educational needs and disabilities. British Journal of Special Education 2015:n/a-n/a.

8. Legal help [https://w3.cerebra.org.uk/help-and-information/legal-entitlements-researchproject/]

9. Disability Living Allowance (DLA) guide [http://w3.cerebra.org.uk/help-andinformation/guides-for-parents/dla-guide/]

10. Parliamentary Inquiry into childcare for disabled children: Levelling the playing field for families with disabled children and young people.

http://www.cafamily.org.uk/media/775031/parliamentary inquiry into childcare web.pdf; 2014.

11. Changing Places [http://www.changing-places.org/]

12. ContactaFamily: What makes my family stronger A report into what makes families with disabled children stronger - socially, emotionally and practically.

http://www.cafamily.org.uk/media/392373/research and reportswhat makesmyfamilystro ngerwhatmakes families with disabled children stronger socially emotionally and prac tically2009.pdf 2009.

13. Haslam SA, Jetten J, Postmes T, Haslam C: Social Identity, Health and Well-Being: An Emerging Agenda for Applied Psychology. Applied Psychology 2009, 58:1-23.

14. Shilling V, Morris C, Thompson-Coon J, Ukoumunne O, Rogers M, Logan S: Peer support for parents of children with chronic disabling conditions: a systematic review of quantitative and qualitative studies. Dev Med Child Neurol 2013, 55:602-609.

15. Salzer MS, Shear SL: Identifying consumer-provider benefits in evaluations of consumerdelivered services. Psychiatr Rehabil J 2002, 25:281-288.

16. Solomon P: Peer support/peer provided services underlying processes, benefits, and critical ingredients. Psychiatr Rehabil J 2004, 27:392-401.

17. Brehaut JC, Kohen DE, Garner RE, Miller AR, Lach LM, Klassen AF, Rosenbaum PL: Health among caregivers of children with health problems: findings from a Canadian populationbased study. Am J Public Health 2009, 99:1254-1262.

18. Brehaut JC, Garner RE, Miller AR, Lach LM, Klassen AF, Rosenbaum PL, Kohen DE: Changes over time in the health of caregivers of children with health problems: growth-curve findings from a 10-year Canadian population-based study. Am J Public Health 2011, 101:2308-2316. 
19. Parent carer assessments [http://www.nhs.uk/conditions/social-care-and-supportguide/Pages/carers-assessment.aspx\#parents]

20. Morris $\mathrm{C}$, Shilling $\mathrm{V}$, McHugh $\mathrm{C}$, Wyatt $\mathrm{K}$ : Why it is crucial to involve families in all stages of childhood disability research. Dev Med Child Neurol 2011, 53:769-771. 
Information about conditions:

- NHS Choices www.nhs.uk/pages/home.aspx

- Contact a Family www.cafamily.org.uk/medical-information/conditions/ also provides links to condition-specific support groups

- Rare Diseases rarediseases.org/for-clinicians-and-researchers/resources/rare-diseaseinformation/

Guidance and support:

- SENDirect sendirect.org.uk/

- MenCap www.mencap.org.uk/

- Cerebra w3.cerebra.org.uk/

- Cerebra guide to the Disability Living Allowance (DLA) Claim Form w3.cerebra.org.uk/help-and-information/guides-for-parents/dla-guide/

- Scope www.scope.org.uk/ who also coordinate Face2Face Peer Support programme www.scope.org.uk/support/services/befriending/about-face-2-face

- Portage www.portage.org.uk/

- Communication Matters www.communicationmatters.org.uk/

- I Can (child communication) www.ican.org.uk/

- Council for Disabled Children's Expert Parent Training) http://www.councilfordisabledchildren.org.uk/what-we-do/work-themes/cdc-healthprogrammes/resources-and-information-for-parents

Research summaries for treatments and therapies:

- PenCRU www.pencru.org/evidence/

- Research Autism researchautism.net/autism-interventions

- Cerebral Palsy Alliance www.cerebralpalsy.org.au/about-cerebral-palsy/interventionsand-therapies/

- CanChild canchild.ca/en/resource types/4-reports

Influencing policy and practice

- National Network of Parent Carer Forums www.nnpcf.org.uk/

- Council for Disabled Children www.councilfordisabledchildren.org.uk/

- Every Disabled Child Matters www.edcm.org.uk/

Parent carer health and wellbeing

- Carers' assessments http://www.nhs.uk/conditions/social-care-and-supportguide/Pages/carers-assessment.aspx\#parents

- Wellbeing for Parents and Carers (Australian guide) www.ndis.gov.au/sites/default/files/documents/Wellbeing\%20Resource.pdf

- Contact a Family (advice on parent support groups and guidance on improving parent carers' and child's sleep) http://www.cafamily.org.uk/advice-and-support/

- Carers Club (includes a support guide and advice on healthy eating, physical activity, mental health and relaxation for carers) http://www.carersclub.org/

- Carers Trust https://www.carers.org/help-directory/taking-care-yourself

- Carers UK (advice about health and nutrition for carers) http://www.carersuk.org/helpand-advice/health

- PenCRU Health Parent Carers programme resources www.pencru.org/projectsmeetings/researchprojects/hpcproject/hpcresources 